\title{
Investigation of Contributing Factors to Traffic Crashes and Violations: A Random Parameter Multinomial Logit Approach
}

\author{
Jaeyoung Lee $\mathbb{i}^{\text {, }}$, Xing Li $(\mathbb{D}$, Suyi Mao $(\mathbb{D}$, and Wen Fu \\ School of Traffic and Transportation Engineering, Central South University, Changsha, Hunan 410075, China \\ Correspondence should be addressed to Suyi Mao; suyimao@csu.edu.cn
}

Received 7 July 2021; Revised 1 September 2021; Accepted 27 September 2021; Published 9 October 2021

Academic Editor: Sara Moridpour

Copyright (c) 2021 Jaeyoung Lee et al. This is an open access article distributed under the Creative Commons Attribution License, which permits unrestricted use, distribution, and reproduction in any medium, provided the original work is properly cited.

\begin{abstract}
This study investigates contributing factors to traffic violations by seriousness. The traffic violations are divided into four categories by seriousness (unintentional violation, minor violation, serious violation, and crash with violation). The results of the random parameter multinomial logit model indicate that various factors potentially affect the severity of traffic violations. The key findings include the following: (1) female drivers are more likely to commit minor violations; (2) drivers from an area with a longer travel time to work and a higher proportion of driving to work are more likely to have minor violations and serious violations, while those from the high-income area are less likely; (3) drivers are more likely to be associated with a more minor infraction during the afternoon peak (4 p.m.-6 p.m.). The results from this study are expected to be beneficial for policymakers and traffic police to comprehend the factors affecting violations and implement effective strategies to minimize the number and seriousness of traffic violations.
\end{abstract}

\section{Introduction}

Traffic crashes have been one of the main causes of death over the world. According to the road safety report of the World Health Organization (WHO), almost half of deaths worldwide are related to road transportation, and the number of traffic deaths has gradually increased and reached 1.35 million in 2016, which emphasizes the urgency of improving traffic safety [1]. Simultaneously, traffic violations involving motor vehicles have become more frequent [2]. Multiple research studies have shown that traffic violations and actual traffic crashes are closely related and both have worsened traffic safety [3].

Traditionally, traffic safety has been analyzed using crash data [4-6]. The accessibility, reliability, and completeness of crash data collected by authorities (e.g., police, highway patrol) are the reasons why most researchers have used crash data for traffic safety research. Nevertheless, road segments or intersections without a crash do not necessarily mean that they are safe. The observed number of crashes is extremely small whereas the number of violations is much larger than that of crashes. In the case of Maryland, the number of violations is approximately 30 times larger than that of crashes. Many dangerous situations caused by risky driving behaviors do not always result in a crash. Crashes are extremely rare random events caused by the combination of human, vehicle, and environmental factors. Even though such violations do not result in crashes, they still have a potential for actual crash occurrence. Thus, violation data are worthy of investigation for the in-depth understanding of traffic safety. Furthermore, violation data suffer less from the small observation issue. Reducing the violation rate could significantly reduce the number of crashes [7]. Thus, a better understanding of traffic violation behaviors could provide advantageous contributions to road safety research.

Although traffic violations are equally important for improving traffic safety, they have not been comprehensively studied. A few researchers considered a limited number of factors that might have an impact on violations. Driving emotions, the presence of passengers, and individual differences in drivers are related to the occurrence of traffic violations [8]. The occurrence of traffic crashes and violations is also affected by the demographic and socioeconomic characteristics of an area [4, 9-12]. Several studies have 
indicated that gender [13], race, age [14], weather [15], and driving experience [16] are correlated with traffic violations. There is no in-depth investigation of traffic violations (including crashes) by seriousness, particularly their contributing factors. Many studies applied the ordered logit and multinomial logit model to analyze various factors affecting injury severity of traffic crashes. Nevertheless, none has comprehensively explored the impact of the key risk factors on the severity of traffic violations. Therefore, the authors are motivated to conduct this research to investigate the factors causing the severity of traffic violations including violationinvolved crashes.

This study aims to provide a comprehensive investigation of observed traffic violations' seriousness, accounting for the influence of individual, temporal, and road factors. In addition, this study focuses on the effect of sociodemographic factors including commuting time, median household income, and commuting mode on traffic violations and crashes. The current study has three major contributions. First, this study aims to study the affecting factors of the severity of traffic violations. The violation data are divided into four categories (e.g., unintentional, minor, serious, and violation-involved crashes), and the unintentional violations are the reference. Second, this study establishes a prediction model for the traffic violations by seriousness using violation data. Third, this study comprehensively considers the impact of microscopic and macroscopic factors as well as the unobserved heterogeneity across the observations.

\section{Literature Review}

2.1. Factors Affecting Traffic Violations. Many studies have proved that drivers' individual characteristics such as gender and age play an imperative role in violating traffic regulations. Drivers of different ages and genders do not have the same emotions and operational responses to specific driving environments. There is a high positive correlation between attitude and behavior and it is possible to predict driving behavior by analyzing the characteristics of different drivers [17]. Among all male drivers' violations, the proportion of speed and equipment violations is higher than that of female drivers' violations. Nevertheless, the proportion of serious violations of female drivers' violations is higher than that of male drivers' violations [18]. The age of drivers is also an important factor in traffic violations. Young drivers aged 1617 have a high propensity to commit aggressive violations and in-vehicle interference. Also, those aged 18-24 have a high probability to perform excessive speeding [14]. On the other hand, drivers over 25 years have a safer attitude in driving behavior compared with younger drivers [13].

Moreover, there is a significant difference in obeying the traffic rules by ethnic group. A research study showed that African Americans were less likely than Whites or Hispanics to have a seat belt in secondary cities [19]. The authors asserted that African Americans are less sensitive to the enforcement of secondary laws than whites, and they are more likely to increase seat belt use when the state changes from the secondary law to the primary law. In addition, another study found that African American drivers speed more frequently and engage in more severe speeding compared to Caucasian drivers [20]. However, there exists strong evidence that there are widespread racial disparities in the stop rate, citations, and search rates. In a study investigating the racial disparities in police interactions with the public, Blacks and Hispanics are more possible to be ticketed, searched, and arrested than Caucasian drivers.

Traffic violation patterns are also different in period time. Some researchers established a time-space model of violations at urban intersections. It was concluded that traffic sign violations are concentrated in the afternoon period time (2-4 p.m.) [21]. Moreover, drivers during peak hours and on weekends are more likely to violate traffic rules [22].

2.2. Factors Affecting Traffic Crashes. There are many roads safety literature dedicated to the study of factors affecting crash occurrence and severities. The causes of traffic crashes can be divided into three categories: driver-related, vehiclerelated, and environment-related factors. Several driver demographic characteristics also affect driving safety. Those variables include age, gender, race, driving experience, and education [23]. Researchers used multilevel logistic regression models and concluded that unemployed drivers, young drivers, no seatbelt usage, and African American drivers exhibited a higher level of risk [24]. As the age decreases, the crash rate is higher, and drivers at age of 21-29 are at the highest risk of involving in a crash [25]. Notably, younger female drivers are more likely to be associated with more serious crashes [5]. Those who are unemployed or handicapped in rural areas and residents of southern states in the United States are more likely to die from motor vehicles crashes [26].

Road safety research has also addressed associations between environment and elevated crash risk. Weather conditions are closely related to the seriousness of traffic crashes. Driving on rural roads or major roads, darkness at the crossroads, turning at night, no street lights, high-speed on a dry road, and nonuse of restrictions are more likely to cause serious crashes [27]. On the other hand, it is found that the visual factors should not be negligible as a factor causing a crash. Poor visibility at night and poor visual guidance on the road are the main risk reasons associated with travel by night. The relative risk of a traffic fatality at nighttime is 1.3 times higher than that of daytime [28]. The lighting conditions also have a significant impact. When it is at dusk or dawn, it may cause more serious injuries compared to other lighting conditions [29].

Although many studies have analyzed the factors affecting crashes, a few studies explored factors affecting violations. In particular, no research has investigated factors influencing traffic violations' seriousness. Previous research on traffic violations has mostly focused on the analysis of the contributing factors to violations and only individual microscopic or macroscopic factors are considered. To account for the possibility of unobserved heterogeneity in the traffic violation data, a random parameter multinomial logit model is applied. To sum up, the main objective of this study is to analyze the affecting factors including individual 
characteristics, time factors, socioeconomic factors, and road characteristics of traffic violations' seriousness by four levels (i.e., unintentional violation, minor violation, serious violation, and crash with violation). Also, several effective strategies for minimizing the number and seriousness of traffic violations are provided.

\section{Data}

Traffic violation data of 2018 were collected from Montgomery County, Maryland. All the violation data were investigated and archived by police in the county on a standard form by state law. Socioeconomic characteristics data were obtained from the United States Census Bureau, 2018 American Community Survey. The processed dataset includes violation types, individual, crash, road, and environmental and socioeconomic characteristics. Besides, we screened and classified traffic violation types based on the police's description. For example, the traffic violation incident (i.e., reckless driving vehicle in wanton and willful disregard for the safety of persons and property, driving left of roadway center in overtaking, and passing when unsafe) appearing in the description will be classified as aggressive driving with the fields of aggressive driving. The classifications of violations are summarized in Table 1.

Figure 1 shows the proportion of traffic violations by their seriousness. The traffic violation dataset includes 34,019 cases after removing erroneous and missing observations. The violations are divided into four infraction-seriousness levels: unintentional violations, minor violations, serious violations, and crash with violations. The proportions of minor and serious violations are $77.48 \%$ and $10.95 \%$, respectively. The vehicle breakdown violations were defined as unintentional violations. Drivers may be issued a safety equipment repair order (SERO) for defective safety equipment for motor vehicles registered in Maryland. It was vehicles registered in Maryland. It was assumed that the vehicle failure-related violations (e.g., reversing system failure, brake system failure, and tire failure) are unintentional violations. The violation responsibility was determined using driver violation-related factors. All drivers involving in a crash in this study are considered to violate traffic rules. In addition, eight types of traffic violations including excessive speeding, right of way violation, not respecting pedestrian crossing, using phone, improper lane change, not respecting a traffic sign, aggressive driving, and alcohol/drug driving have also been considered. Among the eight traffic violations, excessive speeding (36.77\%), not respecting a traffic sign (13.54\%), and using a phone $(10.75 \%)$ account for the largest proportion. Since each state has a different classification rule for the seriousness of violations, there is no uniform classification standard. In this study, the eight types of violations were classified by seriousness based on the proportion of court citations received. Table 1 shows that aggressive driving and alcohol/drug driving were defined as a serious offense and the remaining six types of traffic violations as minor offenses. Consistent with classification results from many states' Department of Motor Vehicles (DMV) and insurance companies, it will be classified to be major violations when eight driving behaviors including alcohol/drug driving, driving without an invalid license, reckless driving, speed race, use of a vehicle to commit a felony, running the scene of crashes, refusing or fleeing from a law enforcement officer, and vehicular homicide happened. However, minor violations are often the most frequent traffic violations you received that are not considered to be a major or serious offense, including speeding and noncompliance with traffic lights. Therefore, this can ensure the rationality of the classification of violations severities. The descriptive statistics of potential independent variables are shown in Table 2.

The remainder of the current paper proceeds with a description of the method used in the current research for a completer understanding of traffic violations. The results are reported and discussed. This paper concludes with a summary of the results and suggestions for future research.

\section{Methodology}

In this section, the theoretical framework of a random parameter multinomial logit model is introduced, which can accommodate both the discrete nature of the dependent variable and the taste allowing possible randomness of parameter variations. Since the severity of traffic violations is a dependent variable with discrete characteristics, the discrete choice model is a suitable method for this research. The application of the random parameter multinomial logit model was undertaken by considering violations' seriousness (i.e., unintentional violation, minor violation, serious violation, and crash with violation).

Referring to Train, the violations severity utility probability function $\left(Y_{\text {in }}\right)$ determining violation severity outcome is defined as $[30,31]$

$$
Y_{\text {in }}=\beta_{i} X_{\text {in }}+\varepsilon_{\text {in }},
$$

where $Y_{\text {in }}$ is a vector of variables determining the violations' seriousness outcome $i$ for violation-involved driver $n, X_{i n}$ is the vector of independent variables (i.e., individual, temporal, road, and sociodemographic factors) for violations' seriousness category $i$ for violation $n ; \beta_{i}$ is a vector of parameters of these observed variables; and $\varepsilon_{i n}$ is an error term. If $\varepsilon_{\text {in }}$ are assumed to be generalized extreme value distributed, then a standard multinomial logit model is as follows [32]:

$$
P_{n}(i)=\frac{\exp \left[\beta_{i} X_{\text {in }}\right]}{\sum_{I} \exp \left[\beta_{i} X_{I n}\right]},
$$

where $P_{n}(i)$ is the probability of a particular discrete outcome category $i$ (from the set of all violation categories I) for violation-involved driver $n$. However, each element of $\beta_{i}$ is supposed to be fixed in each of the violations' seriousness categories). The regression coefficient $\left(\beta_{i}\right)$ can be estimated by the standard maximum likelihood estimation method. To generalize this to allow the parameter vector $\beta_{i}$ to vary across individuals, a mixing distribution is introduced giving violations' seriousness outcome probabilities [33]: 
TABLE 1: Descriptive statistics of different violation types.

\begin{tabular}{|c|c|c|c|c|c|c|c|c|}
\hline Classification & Violation type & Citation & $\begin{array}{l}\text { Safety equipment } \\
\text { repair order (SERO) }\end{array}$ & Warning & Sum & Percentage & $\begin{array}{l}\text { Citation/ } \\
\text { sum }\end{array}$ & $\begin{array}{l}\text { Citation/sum by } \\
\text { classification }\end{array}$ \\
\hline $\begin{array}{l}\text { Unintentional } \\
\text { violation }\end{array}$ & Vehicle breakdown & 0 & 470 & 2628 & 3098 & 9.11 & & $0.00 \%$ \\
\hline \multirow{6}{*}{ Minor violation } & $\begin{array}{l}\text { Not respecting a } \\
\text { traffic sign }\end{array}$ & 1168 & 0 & 3437 & 4605 & 13.54 & $25.36 \%$ & \multirow{6}{*}{$35.53 \%$} \\
\hline & $\begin{array}{l}\text { Improper lane } \\
\text { change }\end{array}$ & 700 & 0 & 1804 & 2504 & 7.36 & $27.96 \%$ & \\
\hline & Using phone & 1458 & 0 & 2200 & 3658 & 10.75 & $39.86 \%$ & \\
\hline & $\begin{array}{l}\text { Not respecting } \\
\text { pedestrian crossing }\end{array}$ & 144 & 0 & 347 & 491 & 1.44 & $29.33 \%$ & \\
\hline & $\begin{array}{l}\text { Right of way } \\
\text { violation }\end{array}$ & 1148 & 0 & 1444 & 2592 & 7.62 & $44.29 \%$ & \\
\hline & Excessive speeding & 4747 & 0 & 7761 & 12508 & 36.77 & $37.95 \%$ & \\
\hline \multirow[b]{2}{*}{ Serious violation } & Aggressive driving & 656 & 0 & 242 & 898 & 2.64 & $73.05 \%$ & \multirow[b]{2}{*}{$93.08 \%$} \\
\hline & $\begin{array}{l}\text { Alcohol/drug } \\
\text { driving }\end{array}$ & 2812 & 0 & 16 & 2828 & 8.31 & $99.43 \%$ & \\
\hline \multirow{2}{*}{ Crash } & $\begin{array}{l}\text { Crash with } \\
\text { violation }\end{array}$ & 799 & 0 & 38 & 837 & 2.46 & \multicolumn{2}{|r|}{$95.46 \%$} \\
\hline & Total & 13,632 & 470 & 19,917 & 34,019 & 100.00 & \multicolumn{2}{|r|}{$100.00 \%$} \\
\hline
\end{tabular}

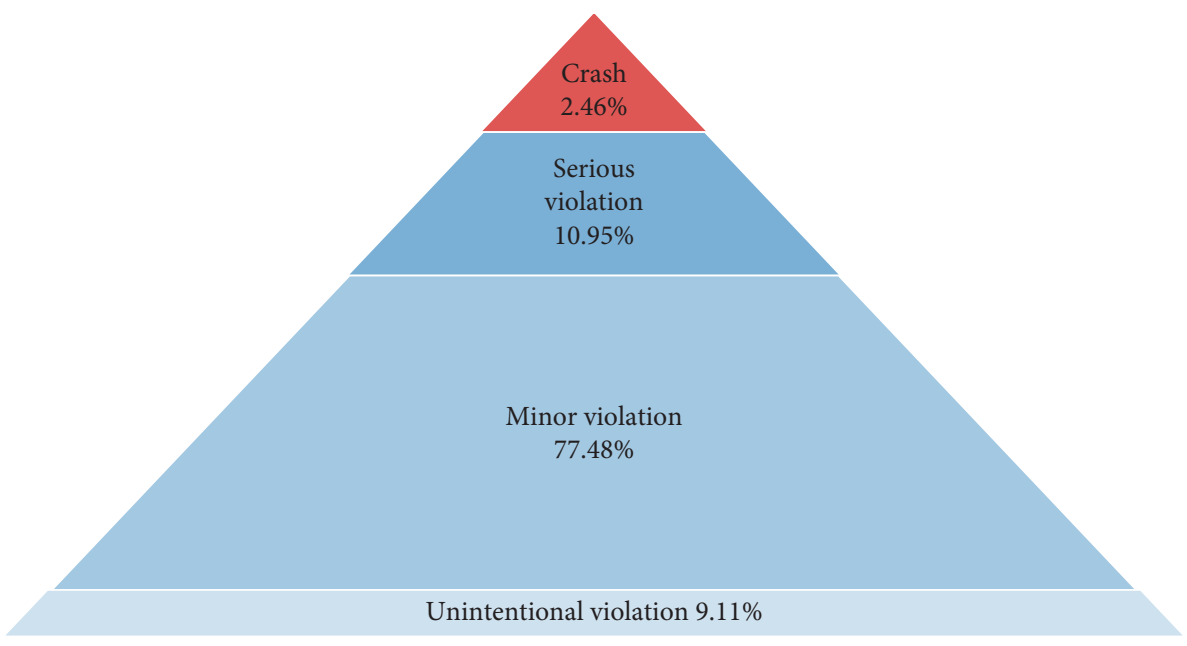

FIgURe 1: Proportion of traffic infractions' severity in the dataset.

$$
P_{\text {in }}(i \mid \varphi)=\int \frac{\exp \left[\beta_{i} X_{i n}\right]}{\sum_{I} \exp \left[\beta_{i} X_{I n}\right]} f\left(\beta_{i} \mid \varphi\right) \mathrm{d} \beta_{i},
$$

where $f\left(\beta_{i} \mid \varphi\right)$ is the density function of $\beta_{i}$, and $\varphi$ is the vector of parameters for the assumed distribution (e.g., the normal distribution), and all other terms are as defined previously. The parameter estimations under equation (3) can account for individual-specific variations on the violation probabilities. The importance of accounting for the unobserved heterogeneity across observations in the analysis of vehicle violation and crash data has been underscored in many existing studies $[3,9,11,34,35]$. In this study, this RPL model was fitted while considering the normal, uniform, and lognormal distributions of the random parameters. These distributions may allow for individual-level variations of the effects of $X$ on the resultant injury severity as opposed to a single $\beta_{i}$ on behalf of the entire sample population, which accounts for the influence of these unobserved variables. In instances where $\beta$ is allowed to vary, some elements of the vector $\beta$ may be fixed and some may be randomly distributed, such as gender, ethnicity, and socioeconomic factors $[34,35]$.

\section{Modelling Results}

Two models for traffic violations by seriousness were developed. The model performances were assessed using AIC, BIC, and McFadden's pseudo $R^{2}$ (Table 3 ). It was shown that the random parameter multinomial logit model performs better than the nonrandom parameter model in terms of AIC, BIC, and McFadden's pseudo $R^{2}$.

Table 4 shows the results of the random parameters multinomial logit model estimation for traffic violations by seriousness, and Table 5 indicates the direct pseudoelasticity effects for the random parameter multinomial logit model. Since unintentional violation is the base case, only three 


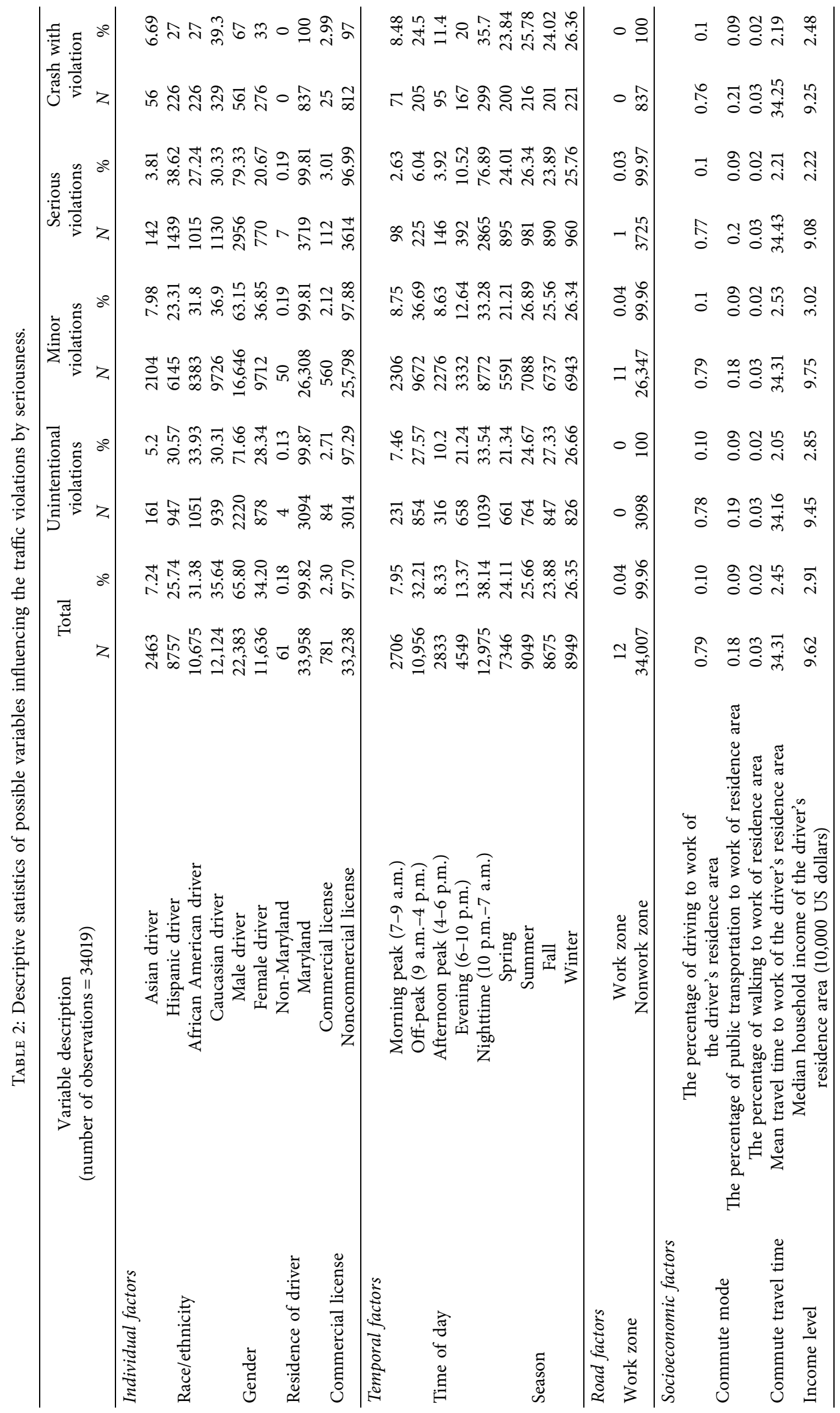


TABLE 3: Model performances for multinomial logit models $(N=34,019)$.

\begin{tabular}{lcc}
\hline Model parameter & Multinomial logit model & Random parameters multinomial logit model \\
\hline Number of parameters $(K)$ & 16 & 19 \\
AIC & 50183.4 & 50152.5 \\
BIC & 50318.4 & 50312.7 \\
Log-likelihood function of the intercept-only model & & -25489.8068 \\
Log-likelihood of the model & -25075.69812 & -25057.23749 \\
McFadden's pseudo $R^{2}$ & 0.01625 & 0.01697 \\
Like-likelihood test: $\chi^{2}(p)$ & 828.21736 & 865.13862 \\
\end{tabular}

TABLE 4: Estimation results of the random parameters multinomial logit model for the seriousness of traffic violations.

\begin{tabular}{|c|c|c|c|c|c|c|}
\hline \multirow[b]{2}{*}{ Characteristic } & \multicolumn{2}{|c|}{ Minor violation } & \multicolumn{2}{|c|}{ Serious violation } & \multicolumn{2}{|c|}{ Crash with violations } \\
\hline & $\begin{array}{l}\text { Parameter } \\
\text { estimate }\end{array}$ & $\begin{array}{l}\text { Standard } \\
\text { deviation }\end{array}$ & $\begin{array}{l}\text { Parameter } \\
\text { estimate }\end{array}$ & $\begin{array}{l}\text { Standard } \\
\text { deviation }\end{array}$ & $\begin{array}{l}\text { Parameter } \\
\text { estimate }\end{array}$ & $\begin{array}{l}\text { Standard } \\
\text { deviation }\end{array}$ \\
\hline $\begin{array}{l}\text { Constant } \\
\text { (Std. dev. constant) }\end{array}$ & $-0.368^{* * *}$ & 0.033 & $2.600^{* * *}$ & 0.041 & $\begin{array}{c}2.423^{* * *} \\
1.238^{* *}\end{array}$ & $\begin{array}{l}0.574 \\
0.557\end{array}$ \\
\hline $\begin{array}{l}\text { Gender } \\
\text { Female } \\
\text { (Std. dev. female) }\end{array}$ & $0.446^{* * *}$ & 0.057 & $-0.869^{* * *}$ & 0.046 & $\begin{array}{l}-0.917^{*} \\
0.773^{* *}\end{array}$ & $\begin{array}{l}0.487 \\
0.329\end{array}$ \\
\hline $\begin{array}{l}\text { Race/ethnicity } \\
\text { African American } \\
\text { (Std. dev. African American) } \\
\text { Hispanic }\end{array}$ & $0.112^{* *}$ & 0.044 & $\begin{array}{l}1.537^{* * *} \\
3.013^{* * *}\end{array}$ & $\begin{array}{l}0.391 \\
0.565\end{array}$ & & \\
\hline $\begin{array}{l}\text { Time period factors } \\
\text { Afternoon peak ( } 4-6 \text { p.m.) } \\
\text { Evening ( } 6-10 \text { p.m.) }\end{array}$ & $0.343^{* * *}$ & 0.068 & & & $0.519^{* * *}$ & 0.105 \\
\hline $\begin{array}{l}\text { Seasonal factors } \\
\text { Fall }\end{array}$ & & & $-0.207^{* * *}$ & 0.042 & & \\
\hline $\begin{array}{l}\text { Commute mode } \\
\text { The percentage of driving to work of the } \\
\text { driver's residence area (ZIP) }\end{array}$ & $0.151^{* * *}$ & 0.025 & $0.228^{* * *}$ & 0.019 & & \\
\hline $\begin{array}{l}\text { Commute travel time } \\
\text { Mean travel time to work of the driver's } \\
\text { residence area }\end{array}$ & $0.074^{* * *}$ & 0.026 & $0.043^{* *}$ & 0.020 & & \\
\hline $\begin{array}{l}\text { Household income } \\
\text { Median household income of the } \\
\text { driver's residence area }\end{array}$ & $-0.241^{* * *}$ & 0.027 & & & & \\
\hline
\end{tabular}

Note. ${ }^{*},{ }^{* *}$, and ${ }^{* * *}$ indicate significance at $10 \%, 5 \%$, and $1 \%$ levels, respectively. Std. dev.: standard deviation.

severity categories (i.e., minor violation, serious violation, and crash with violation) were included in the model. To reduce the model estimation bias caused by the multicollinearity between explanatory variables, the Pearson correlation coefficient and Kendall's tau-b correlation coefficient between each pair of variables were computed before the model estimation. If two variables were found significantly correlated, they were inputted into the model form one by one while monitoring the overall model fit and the significance of the variable. Additionally, 500 Halton draws were utilized in the parameter estimation procedure since the efficiency of Halton draws was primarily significant compared to random draws. The model estimation results showed that 9 variables are significantly related to the traffic violations' seriousness. The variables of race and gender were found to have random effects and obey normal distribution and lognormal distribution, respectively. All coefficients shown in Table 4 are statically significant at the $90 \%$ confidence level. The remainder of this section presents a further discussion on the estimation results.

5.1. Individual Factors. The occurrence of traffic violations depends on various factors related to the drivers. Only $34.2 \%$ of the 34,019 violation drivers are female. The model estimation results show that gender and race are significantly associated with traffic violations. Males comprise most violations, and $65.8 \%$ of the 34,019 violation drivers were male. The estimations of the female are positive and significant for minor violations $(p<0.01)$ but are negative for serious violations and crash with violations. As shown in Table 5, female drivers' probability of committing minor violations would increase by $13.13 \%$. The effects of female drivers committing the crash with violations are random and have a 
TABLE 5: Estimated elasticity values of the random parameter multinomial logit model for traffic violations by seriousness outcomes, in percent.

\begin{tabular}{|c|c|c|c|c|}
\hline Variable & Unintentional violations (\%) & Minor violations (\%) & Serious violations (\%) & Crash with violations (\%) \\
\hline $\begin{array}{l}\text { Gender } \\
\text { Female }\end{array}$ & -2.11 & 13.13 & -0.97 & -1.76 \\
\hline $\begin{array}{l}\text { Race/ethnicity } \\
\text { African American } \\
\text { Hispanic } \\
\end{array}$ & $\begin{array}{c}7.20 \\
-0.31 \\
\end{array}$ & $\begin{array}{l}7.20 \\
2.56 \\
\end{array}$ & $\begin{array}{c}1.73 \\
-0.31 \\
\end{array}$ & $\begin{array}{c}4.93 \\
-0.29 \\
\end{array}$ \\
\hline $\begin{array}{l}\text { Time period factors } \\
\text { Afternoon peak ( } 4-6 \text { p.m.) } \\
\text { Evening ( } 6-10 \text { p.m.) }\end{array}$ & $\begin{array}{l}-0.49 \\
-0.32\end{array}$ & $\begin{array}{l}2.37 \\
3.43\end{array}$ & $\begin{array}{c}-0.28 \\
0.20\end{array}$ & $\begin{array}{c}-0.44 \\
5.94\end{array}$ \\
\hline $\begin{array}{l}\text { Seasonal factors } \\
\text { Fall }\end{array}$ & 1.79 & -2.16 & -0.62 & -1.67 \\
\hline $\begin{array}{l}\text { Socioeconomic factors } \\
\text { Driving to work } \\
\text { Mean travel time to work } \\
\text { Median household income }\end{array}$ & $\begin{array}{c}0.36 \\
0.09 \\
-0.78 \\
\end{array}$ & $\begin{array}{c}0.16 \\
0.09 \\
-0.78 \\
\end{array}$ & $\begin{array}{c}0.11 \\
0.02 \\
-0.31 \\
\end{array}$ & $\begin{array}{c}0.08 \\
0.07 \\
-0.68 \\
\end{array}$ \\
\hline
\end{tabular}

mean of 0.773 and a standard deviation of 0.329 . The lognormal distribution curve indicates that $88.22 \%$ of the female drivers will have a lower probability of involving in a crash with violations than males. However, about $11.78 \%$ of the female drivers would have a higher probability of involving in a crash with violations.

It is noteworthy that there are dissimilarities between the Asian, African American, Caucasian, and Hispanic drivers. The model results show that drivers of Hispanic have more minor violations. Hispanic drivers were $2.56 \%$ more likely to commit minor violations, $0.31 \%$ less likely to commit serious violations, and $0.29 \%$ less likely to involve in a crash with violations, respectively. African American drivers had an increased likelihood of minor violations and serious violations by $7.20 \%$ and $1.73 \%$, respectively. Different from traditional models, the parameters estimated from the random model were represented by a normal distribution. The results confirm the unobserved heterogeneous effects among African American drivers; this random parameter is normally distributed with a mean of 3.013 and a standard deviation of 0.565 . This means that, for the majority (69.5\%) of serious violations during the analysis period, African American drivers increased the likelihood of serious violations outcome, while, for 30.5\%, the African American drivers decreased the likelihood of serious violations outcome.

5.2. Temporal Factors. Specific road environments in different seasons have effects on the drivers' perception and driving behavior, which also has a significant impact on the traffic violations' seriousness. The effects of fall are negative and significant at $p<0.01$ for involving in a crash with violations. Compared with spring, summer, and winter, more serious violations are less likely to occur in fall. The result showed the possibility of committing serious violations in the four seasons in fall is the least. Violations that occurred in fall have lower chances of resulting in more serious violations but a $1.79 \%$ increase in the likelihood of being unintentional violations. In view of temporal characteristics, differences among the five time periods including nighttime, morning peak, afternoon peak, evening, and off-peak with each traffic violations' seriousness level can be observed. The afternoon peak indicator variable (1 if violations occurred during the afternoon peak, 0 otherwise) was defined for minor violation function and kept fixed across the observations. The positive sign of this variable implies that it has a higher likelihood to commit minor violations. Afternoon peak driving had an increased likelihood of committing minor violations by $0.49 \%$, a decreased likelihood of committing serious violations, and crash violations by $0.28 \%$ and $0.44 \%$, respectively. The effects of the evening are found to be positive for involving in a crash with violations and significant at $p<0.01$. Evening driving would be associated with an increased likelihood of crash with violation involvement. Compared with other time periods, more serious violations are more likely to occur in the evening. The probability of committing minor violations, serious violations, and crash with violations, respectively, increases by $3.43 \%, 0.20 \%$, and $5.94 \%$ while driving in the evening compared to other time periods, respectively. The reason might be that driving in darkness will increase fatigue and the risk of collision.

5.3. Socioeconomic Factors. Commuting mode, median household income, and commuting time are found to be contributory to the seriousness of traffic violations. The results show that the proportion of the effects of driving to work is positive and significant for committing minor violations and serious violations $(p<0.01)$. Violations occur in an area with a high proportion of trips among the modes of travel, the likelihood of committing minor violations, serious violations and crash with violation increase by $0.16 \%$, $0.11 \%$, and $0.08 \%$, respectively. Another finding is that cities with a longer mean travel time to work are more likely to cause minor violations and serious traffic violations. The estimation results show that, for violations occurring in an area with high mean travel time to work, the likelihood of committing minor violations and serious violations 
increases by $0.09 \%$ and $0.02 \%$, respectively. In addition, the income level of urban residents is also a nonnegligible factor affecting the occurrence of traffic violations. The median household income of the driver's residence has negative effects on minor violations, and it is significant $(p<0.01)$. The higher median household income of the driver's residence would be associated with a decreased likelihood of all types of traffic violations.

\section{Discussion}

Research on traffic violations' contributing factors for improving traffic safety is essential to society. This study explored the effects of various factors which are found to be significant in the random parameter multinomial logit model for traffic violations by seriousness. Individual, temporal, and socioeconomic factors, which were found significant, are discussed in the following sections.

6.1. Individual Factors. The descriptive statistics indicate that male drivers have a more frequent violation of traffic rules, accounting for $71.66 \%$ of all violations. The gender differences of violation and crash with violation risk have been previously explored. The results of this work confirm that males and females have different performances in traffic violations. The female drivers have a negative pseudoelasticity value in serious violations and crash with violation outcomes but a positive pseudoelasticity value in minor violations, revealing that male drivers are more prone to commit serious violations or even cause a crash with violations, but minor violations are the opposite. This is not an astonishing phenomenon; however, in light of the plethora of evidence documenting higher levels of aggression in males who have higher scores on aggressive driving of driving exposure than in females [18]. Furthermore, the risk of a crash with violation per mile for men is always higher than that for women in different light condition situations [36]. The above research findings are mutually verified with our results that male drivers are more prone to violate serious violations or even cause crash with violations. Females have a stronger positive correlation between feeling seeking and the frequency of traffic violations. Therefore, female's performance in complying with minor violations is worse than males. Among the violations that are likely to cause traffic crash with violations, the proportion of females who violate the rules is higher than the male. The above research findings are mutually verified with our results. It is worth noting that female drivers are more cautious, which leads to a lower risk of serious violations or even a traffic crash.

Concerning race, the model results show that African American drivers have a higher probability of severe violations, suggesting a higher level of risk-taking among this group. The predominance of African American drivers in road traffic violation statistics can be partially accounted for by differences in exposure to risks, assuming that African American drivers are more likely to commit significantly more traffic violations to drivers than Caucasian drivers. Studies have shown that the police send more issues to or arrest drivers who are racially different from the police [37]. Compared with Caucasian drivers, African American drivers are more likely to be fined, searched, and arrested. Thus, race plays an indirect role in the occurrence of traffic violations by affecting drinking and driving, as well as the interaction with age and gender [38].

6.2. Temporal Factors. Time of day displays statistically significant associations with the seriousness of traffic violations. In the model, a day was divided into five time periods according to the time characteristics including nighttime (10 p.m. -6 a.m.), morning peak (7-9 a.m.), off-peak (9 a.m.-4 p.m.), afternoon peak (4-6 p.m.), and evening (6-10 p.m.). Negative pseudoelasticity value related to periods of afternoon peak for serious violations and crash with violations and positive pseudoelasticity value for minor violations resulted in the increased likelihood of more minor violations. Traffic jams and complicated road conditions caused by heavy traffic during peak hours may be the reasons for the more minor violations. Furthermore, more vehicles on the road result in less possibility of aggressive driving. The result also suggests that evening might be of higher possibility leading to more serious violations. Travel during nighttime is associated with a relative risk of about 1.6 that of the period of off-peak. The possibility of crash with violations in the evening (6-10 p.m.) is $5.94 \%$ higher than during other time periods. Driver fatigue and alcohol use also form a significant component of the higher risk of evening travel. Studies have also determined that the lack of streetlights and poor visibility at night are associated with a significantly higher probability of speeding and drunk driving. Dark conditions, which lead to the slowest rate of improvement in the darkness without street lighting, may also affect the occurrence of traffic violations. The problem of crashes in the dark is not a matter of visibility, but a driver's unique driving habits at night [16].

The occurrence season of traffic violation has a direct impact on violations by seriousness. As shown in Table 5, the negative pseudoelasticity value related to fall for traffic violations resulted in decreased likelihood of minor violations, serious violations, and crash with violations, which is basically consistent with the previous estimation result. It can be explained by the visual psychological load of the driver. The probability of serious violations and crash with violations is greater in summer and spring. Compared with other seasons (i.e., summer, spring, and fall), serious violations and crash with violations are more likely to occur in winter. Especially on an icy road in winter, the driver's parking decision is riskier than normal road conditions. During winter abrupt braking on an icy road can be very dangerous. Because the driver's behavior is different during snowy days, the risk of crashes is higher during winter snowfall compared to nonsnow conditions. More serious summer traffic offenses may be associated with a high temperature. A prior study found that drivers are more likely to drive at higher speeds in high-temperature environments [39]. In addition, further studies have found that deaths are related to traffic accidents mostly most frequently in summer [40], and this consequence confirms the discussion above. 
6.3. Socioeconomic Factors. Regarding the socioeconomic factors of areas, the proportion of driving to work, median household income, and mean travel time to work of the driver's residence are selected as explanatory variables. The estimated model indicates that the three variables mentioned above have a significant association with traffic violations by seriousness. In residence with low-income levels, drivers are more likely to have minor violations, serious violations, and crash with violations. It is possible that drivers from lowincome families are more exposed to crashes with violation because they are less likely to buy newer and safer vehicles [41]. In addition, the researchers found that taxi drivers who did not earn sufficient income have a higher risk of crashes, which may be because they want to improve earnings by working longer hours to support their families [42]. Another possible reason is that the rich regions have more comprehensive traffic control facilities as well as a higher penetration rate of traffic laws for drivers, which can explain that low-income drivers had a higher percentage of do not wear seat belts [43].

Mean travel time and the percentage of driving to work are significant predictors of the traffic violations by seriousness. A residence with a longer mean travel time represents that the location is probably in rural or suburban residential areas far from workplaces. The comprehensive differences in the population (e.g., age and gender, etc.) or socioeconomic (education) composition in urban and rural areas lead to significant differences in drivers' compliance with traffic violations [44]. The number of traffic crashes is positively correlated with the average speed, and as the speed increases, the speed increases too. Drivers generally show higher driving speeds on rural roads than urban roads, so the city with long average travel times has a greater risk of crashes. The model results show that cities with long travel times have a greater risk of minor violations. A residential area with long mean travel times tends to be in suburban or rural areas, and the number of traffic conflicts is smaller than that of urban roads, so these residential areas have a greater risk of serious violations such as red-light running. Drivers living in rural areas are less likely to stop at a stop sign intersection than drivers living in urban areas [45]. This may be because drivers residing in rural areas often go to areas with less traffic and better visibility and may be more likely to not stop. In contrast, in urban areas, those with impaired vision seem to be more cautious about stop signs. A positive sign of the variable with the percentage of driving to work suggests that the high percentage of driving to work increases the traffic violations by seriousness. More vehicles and long travel times indicate an increase in overall urban traffic exposure which may increase the likelihood of traffic violations. From the discussion above, it was shown that very few studies have investigated the relationships between traffic violations and socioeconomic factors. This research can reveal the impact of socioeconomic factors on the severity of violations by incorporating factors such as the proportion of driving to work, median household income, and mean travel time to work of the driver's residence into the model.

\section{Conclusions}

In this research, a random parameters multinomial logit model was adopted in the investigation of traffic violations by seriousness, which are of scholarly and practical importance. By analyzing data of traffic violations, individual and socioeconomic factors in Maryland, the relationships between the factors and violations by seriousness (i.e., unintentional violation, minor violation, serious violation, and crash with violation) were discovered. The major conclusions drawn from this study are summarized as follows:

(1) Female drivers have a higher possibility of minor violations; developing campaigns to raise awareness of careful driving under such circumstances for female drivers is of necessity.

(2) Hispanic drivers have an increased potential to have minor violations but have a slightly lower potential of serious violations and crash with violations.

(3) The socioeconomic features of an area (i.e., mean travel time to work and way of travel) are more influential in determining driving behavior, with some determinants having a positive correlation across the violations by seriousness. Traffic management departments should strengthen education on traffic safety related to minor violations in cities with long average travel times.

(4) In residence with low-income levels, drivers are more likely to have minor violations, serious violations, and crash with violations.

(5) During the evening, it is more likely to have serious violations. According to the results of the violation data analysis, different recommendations can set up more warning signs and make related policies to mitigate traffic violation rates in the states.

(6) Two factors, that is, female and African American, were found to have random effects on the probability of violation seriousness, which addressed the unobserved heterogeneity issues existing among the population of violation.

The findings of this study have important implications to enhance safe driving practices. This paper contributes to providing ideas on how to reduce traffic violations and their severity. Based on the findings from the study, policymakers can propose appropriate preventive measures and facilitating the development of violations' seriousness mitigation policies. There are several possible extensions for this study. It uses a relatively small database from a single state. Further research on the seriousness of traffic violations using databases from multiple states may generate other statistically important factors that can better explain the seriousness of violations. In addition, due to the limited data used in this study, the driver's age, weather, vehicle characteristics, pavement condition, and other factors were not able to be considered. Moreover, changes in traffic violations under the intelligent connected vehicle environment are anticipated in the near future. Thus, conflicts between conventional and 
intelligent connected vehicles and the relevant violation behaviors should be explored in the future.

\section{Data Availability}

Traffic violation data of Montgomery County, Maryland, from 2012 to 2018, are publicly available, https://data. montgomerycountymd.gov/Public-Safety/Traffic-

Violations/4mse-ku6q, accessed on September 27, 2021.

\section{Conflicts of Interest}

The authors declare that they have no known competing financial interests or personal relationships that could have appeared to influence the work reported in this paper.

\section{Acknowledgments}

This study was funded by the National Key R\&D Program of China (2020YFB1600400) and Innovation-Driven Project of Central South University (2020CX013).

\section{References}

[1] WHO, Global Status Report on Road Safety 2018: Summary, WHO, Geneva, Switzerland, 2018.

[2] R. Mishra, P. Kumaraguru, R. R. Shah, and A. Sadaria, "Analyzing traffic violations through e-challan system in metropolitan cities (workshop paper)," in Proceedings of the 2020 IEEE Sixth International Conference on Multimedia Big Data (BigMM), pp. 485-493, New Delhi, India, September 2020.

[3] M. Feng, X. Wang, and M. Quddus, "Developing multivariate time series models to examine the interrelations between police enforcement, traffic violations, and traffic crashes," Analytic Methods in Accident Research, vol. 28, Article ID 100139, 2020.

[4] J. Lee, M. Abdel-Aty, and K. Choi, "Analysis of residence characteristics of at-fault drivers in traffic crashes," Safety Science, vol. 68, pp. 6-13, 2014.

[5] J. Lee, J. Chae, T. Yoon, and H. Yang, "Traffic accident severity analysis with rain-related factors using structural equation modeling-a case study of Seoul city," Accident Analysis and Prevention, vol. 112, pp. 1-10, 2018.

[6] M.-s. Li and H.-l. Huang, "Road-safety recognition and network equilibrium with perceived route-choice sets," Transportation Safety and Environment, vol. 1, no. 2, pp. 126-134, 2019.

[7] G. Zhang, K. K. W. Yau, and G. Chen, "Risk factors associated with traffic violations and accident severity in China," Accident Analysis and Prevention, vol. 59, pp. 18-25, 2013.

[8] L. Precht, A. Keinath, and J. F. Krems, "Identifying the main factors contributing to driving errors and traffic violationsresults from naturalistic driving data," Transportation Research Part F: Traffic Psychology and Behaviour, vol. 49, pp. 49-92, 2017.

[9] J. Lee, M. Abdel-Aty, and Q. Cai, "Intersection crash prediction modeling with macro-level data from various geographic units," Accident Analysis and Prevention, vol. 102, pp. 213-226, 2017.

[10] C. Han, H. Huang, J. Lee, and J. Wang, "Investigating varying effect of road-level factors on crash frequency across regions: a Bayesian hierarchical random parameter modeling approach," Analytic Methods in Accident Research, vol. 20, pp. 81-91, 2018.

[11] J. Lee and T.-H. T. Gim, "A spatial econometrics perspective on the characteristics of urban traffic accidents: focusing on elderly drivers' accidents in Seoul, South Korea," International Journal of Injury Control and Safety Promotion, vol. 27, no. 4, pp. 520-527, 2020.

[12] J. Lee, M. Abdel-Aty, M. R. de Blasiis, X. Wang, and I. Mattei, "International transferability of macro-level safety performance functions: a case study of the United States and Italy," Transportation Safety and Environment, vol. 1, no. 1, pp. 68-78, 2019.

[13] S. Bachoo, A. Bhagwanjee, and K. Govender, "The influence of anger, impulsivity, sensation seeking and driver attitudes on risky driving behaviour among post-graduate university students in Durban, South Africa," Accident Analysis and Prevention, vol. 55, pp. 67-76, 2013.

[14] H. M. Hassan and M. A. Abdel-Aty, "Exploring the safety implications of young drivers' behavior, attitudes and perceptions," Accident Analysis and Prevention, vol. 50, pp. 361-370, 2013.

[15] J. C. F. de Winter and D. Dodou, "National correlates of selfreported traffic violations across 41 countries," Personality and Individual Differences, vol. 98, pp. 145-152, 2016.

[16] D. D. Clarke, P. Ward, C. Bartle, and W. Truman, "Young driver accidents in the UK: the influence of age, experience, and time of day," Accident Analysis and Prevention, vol. 38, no. 5, pp. 871-878, 2006.

[17] J. Castellà and J. Pérez, "Sensitivity to punishment and sensitivity to reward and traffic violations," Accident Analysis and Prevention, vol. 36, no. 6, pp. 947-952, 2004.

[18] B. González-Iglesias, J. A. Gómez-Fraguela, and M. Á. Luengo-Martín, "Driving anger and traffic violations: gender differences," Transportation Research Part F: Traffic Psychology and Behaviour, vol. 15, no. 4, pp. 404-412, 2012.

[19] J. K. Wells, A. F. Williams, and C. M. Farmer, "Seat belt use among African Americans, Hispanics, and whites," Accident Analysis and Prevention, vol. 34, no. 4, pp. 523-529, 2002.

[20] R. Tillyer and R. S. Engel, "Racial differences in speeding patterns: exploring the differential offending hypothesis," Journal of Criminal Justice, vol. 40, no. 4, pp. 285-295, 2012.

[21] Y. Li, M. Abdel-Aty, J. Yuan, Z. Cheng, and J. Lu, "Analyzing traffic violation behavior at urban intersections: a spatiotemporal kernel density estimation approach using automated enforcement system data," Accident Analysis and Prevention, vol. 141, Article ID 105509, 2020.

[22] M. Rezapour and K. Ksaibati, "Application of multinomial and ordinal logistic regression to model injury severity of truck crashes, using violation and crash data," Journal of Modern Transportation, vol. 26, no. 4, pp. 268-277, 2018.

[23] E. Dabbour, O. Dabbour, and A. A. Martinez, "Temporal stability of the factors related to the severity of drivers' injuries in rear-end collisions," Accident Analysis and Prevention, vol. 142, Article ID 105562, 2020.

[24] E. K. Adanu, R. Smith, L. Powell, and S. Jones, "Multilevel analysis of the role of human factors in regional disparities in crash outcomes," Accident Analysis and Prevention, vol. 109, pp. 10-17, 2017.

[25] S. Regev, J. J. Rolison, and S. Moutari, "Crash risk by driver age, gender, and time of day using a new exposure methodology," Journal of Safety Research, vol. 66, pp. 131-140, 2018.

[26] R. B. Noland and M. L. Laham, "Are low income and minority households more likely to die from traffic-related crashes?" Accident Analysis and Prevention, vol. 120, pp. 233-238, 2018. 
[27] Y. Wang and W. Zhang, "Analysis of roadway and environmental factors affecting traffic crash severities," Transportation Research Procedia, vol. 25, pp. 2119-2125, 2017.

[28] W. Ackaah, B. A. Apuseyine, and F. K. Afukaar, "Road traffic crashes at night-time: characteristics and risk factors," International Journal of Injury Control and Safety Promotion, vol. 27, no. 3, pp. 392-399, 2020.

[29] J. Lee, M. Abdel-Aty, Q. Cai, and L. Wang, "Effects of emergency medical services times on traffic injury severity: a random effects ordered probit approach," Traffic Injury Prevention, vol. 19, no. 6, pp. 577-581, 2018.

[30] M. Weeks, Discrete Choice Methods with Simulation, K. E. Train, Ed., Cambridge University Press, Cambridge, UK, 2003.

[31] J. Zhang and J. Lee, "Interactive effects between travel behaviour and COVID-19: a questionnaire study," Transportation Safety and Environment, vol. 3, no. 2, pp. 166-177, 2021.

[32] M. S. B. Shaheed, K. Gkritza, W. Zhang, and Z. Hans, "A mixed logit analysis of two-vehicle crash severities involving a motorcycle," Accident Analysis and Prevention, vol. 61, pp. 119-128, 2013.

[33] F. Ye, C. Wang, W. Cheng, and H. Liu, "Exploring factors associated with cyclist injury severity in vehicle-electric bicycle crashes based on a random parameter logit model," Journal of Advanced Transportation, vol. 2021, Article ID 5563704, 12 pages, 2021.

[34] S. S. Ahmed, S. S. Pantangi, U. Eker, G. Fountas, S. E. Still, and P. C. Anastasopoulos, "Analysis of safety benefits and security concerns from the use of autonomous vehicles: a grouped random parameters bivariate probit approach with heterogeneity in means," Analytic Methods in Accident Research, vol. 28, Article ID 100134, 2020.

[35] A. Behnood and F. Mannering, "Determinants of bicyclist injury severities in bicycle-vehicle crashes: a random parameters approach with heterogeneity in means and variances," Analytic Methods in Accident Research, vol. 16, pp. 35-47, 2017.

[36] D. L. Massie, P. E. Green, and K. L. Campbell, "Crash involvement rates by driver gender and the role of average annual mileage," Accident Analysis and Prevention, vol. 29, no. 5, pp. 675-685, 1997.

[37] J. M. MacDonald and J. Fagan, "Using shifts in deployment and operations to test for racial bias in police stops," AEA Papers and Proceedings, vol. 109, pp. 148-151, 2019.

[38] E. Romano, R. Voas, and S. Tippetts, "Stop sign violations: the role of race and ethnicity on fatal crashes," Journal of Safety Research, vol. 37, no. 1, pp. 1-7, 2006.

[39] M. Sutela and M. Aaltonen, "Effects of temporal characteristics and weather conditions on speeding sanction rates in automatic traffic enforcement," Police Journal: Theory, Practice and Principles, 2020.

[40] F. Tuncez, U. E. Bilgin, E. Saruhan, H. S. Yilmazer, and M. Tokdemir, "Evaluation of forensic autopsies performed on fatal traffic accidents in Izmir," Medicine Science|International Medical Journal, vol. 10, no. 2, 2021.

[41] J. Lee, M. Abdel-Aty, and X. Jiang, "Development of zone system for macro-level traffic safety analysis," Journal of Transport Geography, vol. 38, pp. 13-21, 2014.

[42] Q. N. La, A. H. Lee, L. B. Meuleners, and D. Van Duong, "Prevalence and factors associated with road traffic crash among taxi drivers in Hanoi, Vietnam," Accident Analysis and Prevention, vol. 50, pp. 451-455, 2013.
[43] A. Bener, K. Jadaan, D. Crundall, and A. Calvi, "The effect of aggressive driver behaviour, violation and error on vehicle crashes involvement in Jordan," International Journal of Crashworthiness, vol. 25, no. 3, pp. 276-283, 2019.

[44] S. Eiksund, "A geographical perspective on driving attitudes and behaviour among young adults in urban and rural Norway," Safety Science, vol. 47, no. 4, pp. 529-536, 2009.

[45] L. Keay, S. Jasti, B. Munoz et al., "Urban and rural differences in older drivers' failure to stop at stop signs," Accident Analysis and Prevention, vol. 41, no. 5, pp. 995-1000, 2009. 